\title{
The Use of Auditory Event-Related Potentials in Alzheimer's Disease Diagnosis
}

\author{
Fabrizio Vecchio ${ }^{1}$ and Sara Määttä² \\ ${ }^{1}$ Associazione Fatebenefratelli per la Ricerca, Dipartimento Neuroscienze, Ospedale Fatebenefratelli, Isola Tiberina, Rome, Italy \\ ${ }^{2}$ Department of Clinical Neurophysiology, Kuopio University Hospital, Kuopio, Finland
}

Correspondence should be addressed to Fabrizio Vecchio, fabrizio.vecchio@uniroma1.it

Received 30 December 2010; Accepted 9 March 2011

Academic Editor: Florinda Ferreri

Copyright ( $) 2011$ F. Vecchio and S. Määttä. This is an open access article distributed under the Creative Commons Attribution License, which permits unrestricted use, distribution, and reproduction in any medium, provided the original work is properly cited.

\begin{abstract}
Event-related potentials (ERPs) are important clinical and research instruments in neuropsychiatry, particularly due to their strategic role for the investigation of brain function. These techniques are often underutilized in the evaluation of neurological and psychiatric disorders, but ERPs are noninvasive instruments that directly reflect cortical neuronal activity. Previous studies using the P300, P3a, and MMN components of the ERP to study dementing illness are reviewed. The results suggest that particularly the P300 brain potential is sensitive to Alzheimer's disease processes during its early stages, and that easily performed stimulus discrimination tasks are the clinically most useful. Finally, these data suggest that the P300 ERP can aid in the diagnosis of dementia and may help in the assessment of early Alzheimer's disease.
\end{abstract}

\section{Introduction}

Alarmingly increasing prevalence of Alzheimer's disease (AD) due to the aging population in developing countries, combined with lack of standardized and conclusive diagnostic procedures, make accurate diagnosis of Alzheimer's disease, especially for its early stage also known as amnestic mild cognitive impairment (MCI), a major public health concern. While no current medical treatment exists to stop or reverse this disease, recent dementia-specific pharmacological advances can slow its progression, making early diagnosis all the more important. Behaviourally, both $\mathrm{AD}$ and $\mathrm{MCI}$ are traditionally diagnosed in relation to abnormalities in brain functions such as memory, cognition, perception, and language. Furthermore, the differentiation of probable $\mathrm{AD}$ from other dementing illnesses is generally obtained by excluding alternative causes for cognitive dysfunction. It is important therefore to determine whether $\mathrm{AD}$ and MCI can be characterized by functional deficits other than high-level abnormalities already described and whether, with further development, they are specific and sensitive enough to contribute to the search of early markers of the disease process.
In an attempt to facilitate the diagnosis of $\mathrm{AD}$, several noninvasive biomarkers have been proposed, including event-related potentials (ERPs). ERPs are voltage changes time-locked to some physical or mental occurrence in the ongoing electrical brain activity (recorded as EEG). Depending on the type of sensory stimulus, the ERPs can be divided into somatosensory, visual, or auditory ERPs. This review concerns the auditory modality.

In auditory ERP studies, perhaps the most commonly used experimental approach is the active oddball paradigm. In this paradigm, typically two classes of stimuli are presented, one occurring frequently (standard) and the other occurring infrequently (target), and the subject is required to distinguish between the two stimuli and to respond to the stimuli that are predesignated as targets. Variations of this paradigm include the passive oddball paradigm, in which the subject is instructed to ignore the stimuli, and so-called novelty oddball paradigm, in which a third class of stimuli (novelty) are also presented intermixed with the standard and target stimuli.

ERPs offer a psychophysiological method for studying attentional processes, language, and memory functions, yielding information not available from behavioral studies. 
A number of studies have suggested that ERPs are useful indices for assessing changes in cognitive brain functions. In particular, the P300 component of the ERP has been widely applied in the scientific study of age-related cognitive dysfunction, because it reflects attentional and memory processes. This ERP is most commonly elicited in a active oddball paradigm when a subject detects an occasional target stimulus in a regular train of standard stimuli. In the novelty oddball paradigm, in turn, deviant or unexpected tones elicit a frontal subcomponent of P300, namely, the P3a, which is considered as an electrophysiological marker of the orienting response [1]. Furthermore, in the passive oddball paradigm, at around $200 \mathrm{~ms}$ the deviant tones elicit a component called mismatch negativity (MMN). The MMN is thought to reflect the mismatch between a trace in a sensory memory (of the standard stimulus) and the representation of the current stimulus to which the trace is compared, and is considered to be an index of the preattentive stage of auditory information processing [2].

The present paper briefly reviews from the literature (especially from [3]) the background of clinical MMN and P300 applications.

\section{P300 Responses}

Auditory P300, a positive deflection occurring at about $300 \mathrm{~ms}$ from stimulus onset, is one of the most widely studied components of the ERP. It is generated by the activation of multiple neocortical and limbic regions, and has two functionally different components: the earlier P3a that is maximal over frontocentral regions, and the later P3b (hereafter called P300 in this review) that is maximal at posterior scalp locations [4].

\section{Psychophysiology of P300}

The P300 is parietocentral positivity that occurs when a subject detects an informative task relevant stimulus (first described by Desmedt et al. [5]; Sutton et al. [6]). It is most commonly elicited in an active oddball paradigm when a subject detects an occasional target stimulus in a regular train of standard stimuli. The $\mathrm{P} 300$ probably represent concurrent activity in multiple regions of the brain, including temporolparietal neocortical areas and higher limbic structures [716].

The major theoretical interpretation of the P300 component is that it indexes updating of activity in corticolimbic circuits in processes requiring attention and working memory $[17,18]$. This context updating theory has its roots in Sokolov's model of the orienting response, which has been postulated to result from a change in the organism's neural representation of the stimulus [19]. P300 amplitude is also proportional to the amount of attentional resources devoted to a given task [20-22] and has been associated with superior memory performance $[23,24]$. P300 amplitude can therefore be viewed as a measure of CNS activity that reflects the processing of incoming information when it is incorporated into memory representations of the stimulus and the context in which the stimulus occurs. Variation in P300 amplitude is, therefore, assumed to reflect the degree or quality with which that information is processed.

The P300 has a latency to peak of anywhere from 300 to $1000 \mathrm{~ms}$, depending on task complexity and the clinical sample tested. A frequently observed phenomenon is that the P300 latency increases when categorization of the stimulus becomes more difficult. A general consensus seems to be that P300 is evoked after the stimulus has been evaluated [25]. Thus, the latency of P300 has been regarded as a measure of stimulus evaluation time $[26,27])$ and is generally unrelated to response selection processes $[28,29]$. It is therefore independent of behavioral reaction time $[30,31]$. Indeed, it is just these properties that make the P300 a valuable tool for assessing cognitive function: because P300 latency is an index of the processing time required before response generation, it is a sensitive temporal measure of the neural activity underlying the processes of attention allocation and immediate memory. In addition, P300 latency is negatively correlated with mental functions in normal subjects, with shorter latencies associated with superior cognitive performance (e.g., [32-35]). The neuropsychological tests that are best correlated with P300 latency are those that assess how rapidly subjects can allocate and maintain attentional resources. This association is also supported by results indicating that P300 latency increases as cognitive capability decreases from dementing illness [27, 35-40]. Thus, P300 latency is directly associated with cognitive capability in both normal and patient populations.

\section{Clinical Applications of P300}

Changes in the latency, amplitude, and topography of the P300 correlate with clinical findings in a wide range of disorders and brain injuries. Since the P300 has been related to the fundamental cognitive events of stimulus evaluation and immediate memory in normals, and because its peak latency is correlated with neuropsychological tests of cognitive function, this ERP component may provide an objective index of the degree of dementing illness which can be distinguished from the electrophysiological changes found in normal aging. Indeed, the initial suggestion that the P300 component might be a useful tool for investigating cognitive functions came from studies of normal aging and dementia, since peak latency was found to be prolonged in individuals with dementing illness compared to similarly aged normal subjects $[41,42]$. The extent of deviation varied with the aetiology of the disorder, being greatest with metabolic causes and brain tumours and least with degenerative disorders, such as AD [41]. The P300 latency changes were reversed by treatment in patients with metabolic encephalopathy, with latency returning to normal values when the disorder was corrected and cognitive functions were again normal $[43,44]$.

Several studies have now verified that P300 is an objective and sensitive tool for demonstrating cognitive impairment in $\mathrm{AD}$, as these patients have increased P300 latency and decreased P300 amplitude compared to elderly controls 
subjects $[35,45,46]$. $\mathrm{P} 300$ is sensitive to $\mathrm{AD}$ processes already during its early stages [47], and similar P300 alterations have also been demonstrated in MCI [48-50]. P300 amplitude or latency alterations may also identify preclinical changes in participants who are at relatively high risk for $\mathrm{AD}$ because of genetic predisposition $[48,51]$. P300 may thus reveal neurophysiological changes prior to the emergence of clinical deficits, which could advance the early detection and diagnosis of AD.

P300 latency increases systematically as cognitive function becomes worse in dementing illness, even though component size is not directly associated with the degree of mental impairment [27, 40,52]. Recently, in a followup study, it was shown that the abnormalities in P300 in AD and MCI latency correlated with the severity of cognitive impairment. Furthermore, upon followup, one year later after the baseline study, the P300 latencies demonstrated significantly more prolongation than their baseline measures in $\mathrm{AD}$ and $\mathrm{MCI}$ patients, although their neurophysiological evaluation showed no statistical decline, suggesting that the P300 latency may reflect cognitive decline more sensitively than neuropsychological tests in the longitudinal followup of $\mathrm{AD}$ patients [53]. It has also been suggested that P300 latency is a valuable tool for the evaluation of cholinesterase inhibitors treatment in demented patients [54]. However, P300 latency does not seem to be capable of predicting which MCI patients will convert to $\mathrm{AD}[48]$, and therefore seems to have no predictive value for $\mathrm{AD}$ diagnosis.

Some reports have suggested that ERP measures may distinguish between subcortical (e.g., Huntington's and Parkinson's disease) and cortical (Alzheimer's, cerebral vascular accident) dementias $[55,56]$. Other studies have indicated that P300 latency can separate individuals with dementia from those with depression-associated pseudodementia [37, 57].

Associations between P300 latency and the level of cognitive function also have been reported in neurological disorders, in confusional states, and for posttraumatic syndromes (cf. [34, 36, 38, 43, 44, 58-61]). Furthermore, the P300 component has been used to study psychiatric disorders such as alcoholism, depression, and schizophrenia (e.g., [6267]). Taken together, these findings suggest that P300 may be clinically useful as an index of cognitive function, although its diagnostic utility is questionable (cf. $[27,37,40,68]$ ). The P300 continues to be an important signature of cognitive processes such as attention and working memory and of its dysfunction in neurologic and mental disorders [69].

\section{Psychophysiology of P3a}

The $\mathrm{P} 3 \mathrm{a}$ is a frontocentrally maximal positive ERP wave elicited by deviant or unexpected events [4, 70], and it is considered as an electrophysiological marker of the attentional switching, that is, the orienting response [1]. P3a is generated by a complex cerebral network, including the prefrontal, cingulate, temporo-parietal, and hippocampal regions $[7,71-74]$ and it is recorded over widespread anterior and posterior scalp sites [73]. It has been distinguished from
P300 by a shorter peak latency, a more frontally oriented scalp topography and different elicitation conditions [4].

\section{Clinical Applications of P3a}

The P3a is affected in several psychiatric and neurological disorders. An enhanced P3a amplitude over the left frontal region has been found in chronic alcoholism [75]. An enhanced P3a are found in children with depression [76] and ADHD [77]. In addition, patients with closed head injuries show larger P3a amplitudes than control subjects $[78,79]$.

There are only a few studies published about P3a in $\mathrm{AD}$ and the findings have been to some extent inconsistent. Some authors found that $\mathrm{AD}$ patients are characterized by longer P3a latency than control subjects suggesting delayed orientation to deviant stimuli in $\operatorname{AD}[49,80]$. Furthermore, these authors suggested that separation of P3 subcomponents (P3a and P300) by dipole source analysis may increase sensitivity and specificity in correctly detecting $\mathrm{AD}$ patients from healthy subjects $[49,80]$. On the other hand, some authors found no difference in the P3a between $\mathrm{AD}$ patients and controls but instead showed that the P3a was different in $\mathrm{AD}$ patients compared with patients with vascular dementia whereas the P300 was similar in these patients [81].

\section{Psychophysiology of MMN}

The mismatch negativity (MMN) is a frontal negativity at around $100-200 \mathrm{~ms}$. It is generated automatically whenever the stimulus deviates physically from the immediately preceding context $[82,83]$. MMN can be elicited by changes in simple tones, such as frequency or duration, and also by complex sounds such as phonemes [2]. The MMN is commonly derived by subtracting the ERP to the standard stimulus from that to the deviant stimulus. The MMN is thought to reflect the mismatch between a trace in a sensory memory (of the standard stimulus) and the representation of the current stimulus to which the trace is compared and is considered to be an index of the preattentive stage of auditory information processing [2]. In addition, by measuring the decay of the MMN amplitude as a function of the interstimulus interval, it is possible to estimate the duration of sensory memory. The MMN is generated mainly in the auditory cortex in the temporal lobes $[84,85]$. Furthermore, a frontal MMN generator [86], has also been implicated.

\section{Clinical Applications of MMN}

MMN is an important ERP measure as it may reveal deficits of both sensory memory storage and of fundamental automatic mismatch detection mechanism [87, 88]. MMN is attention independent and therefore particularly suitable for studies with subjects who do not cooperate at all or cooperate very poorly. Clinical research lines using the MMN involve schizophrenia, dyslexia, autism spectrum disorders, coma, alcoholism, and dementia (for a review, see [89]). 
Early studies on the aging effects on the MMN show that the MMN is smaller and prolonged in the ERPs of the normal old compared to those of the young (e.g., [90, 91]). In subsequent studies, Pekkonen et al. [92, 93] found that with frequency changes this effect was confined to conditions with long inter-stimulus intervals (ISIs), indicating that it is sensory memory rather than perception that is affected by aging. Similarly, several studies have found fairly unaffected MMN in AD at short ISIs [94]; (for review, see [95]), whereas MMN was reduced at long (3s) ISI in these patients [96]. These results suggest that $\mathrm{AD}$ appears to reduce the duration of auditory sensory memory when sound frequency is involved.

Interestingly, the pattern with duration $\mathrm{MMN}$ is quite different, with the age-related $\mathrm{MMN}$-amplitude decrement being present even with short ISIs (for a review, see [95]). However, in patients with $\mathrm{AD}$ automatic stimulus discrimination to duration change in the auditory cortex is preserved as compared with normal aging [97]. These findings imply that although the preattentive discrimination to duration deviance is attenuated in aging, it is not further damaged in the early phase of AD. This may be due to the fact that the neurodegenerative changes underlying $\mathrm{AD}$ mainly affect mesial temporal structures like hippocampus, whereas the lateral aspects of the temporal lobes, where the MMN is generated, are less damaged [97].

In summary, studies on $\mathrm{MMN}$ in $\mathrm{AD}$ demonstrate that older controls and patients with $\mathrm{AD}$ produce MMNs that are reduced in amplitude relative to the younger subjects, but the differences between older controls and $\mathrm{AD}$ subjects are relatively small. Also, the fact that the $\mathrm{AD}$ subjects can produce significant $\mathrm{MMN}$ responses suggest that they do have a relatively intact MMN, albeit reduced in amplitude compared to controls [94]. In all the aforementioned studies, patients had minor to moderate cognitive impairment and taking into account the acknowledged cholinergic hypothesis in $\mathrm{AD}$, probably their cholinergic defect was not sufficient to cause MMN generator impairment per se at short ISIs, but in some studies, impaired the duration of the memory trace [96].

As reviewed here, the value of the MMN in the early diagnosis of $\mathrm{AD}$ is somewhat limited. However, more pronounced MMN alterations have been found in demented Parkinson's disease (PD) patients relative to normal controls or patients with $\mathrm{AD}$ and dementia with Lewy-bodies, indicating that demented PD patients to a larger degree than the control groups have a deficit in automatic auditory change detection [98]. Furthermore, MMN may aid in the differentiation of normal pressure hydocephalus (NPH) from NPH with concomitant AD [99]. Thus, the MMN may aid in the differentiation of $\mathrm{AD}$ from other dementing illnesses. These findings also have implications for understanding cognitive and behavioural functioning in patients with dementia.

\section{Conclusion}

Alzheimer's disease is a neurodegenerative disorder, causing neuronal death that leads to cognitive function decline.
Two misfolded proteins, $\beta$-amyloid that causes plagues and hyperphosphorylated- $\tau$ that causes neurofibrillary tangles are often blamed, yet, the genesis of these proteins, and in fact the true cause of the disease, are still unknown. While no current medical treatment exists to stop or reverse this disease, recent dementia-specific pharmacological advances can slow its progression, making early diagnosis all the more important.

Application of the auditory ERPS to the study of dementing illness and $\mathrm{AD}$ has produced positive findings. The P300 response, in particular, has become popular in studies of dementia. Because the P300 response is related to fundamental aspects of cognitive function in normals, it should be useful in the diagnosis of dementia, especially that of the Alzheimer's type. In general, this assertion is supported by a wide variety of previous findings that include the spectrum of dementias. Although the P300 does not appear to differentiate between types of cortical dementias, it does accurately reflect the level of cognitive dysfunction caused by these disorders. Furthermore, the auditory evoked potentials (including the MMN) might offer an additional tool to index cholinergic dysfunction in aging and in neurodegenerative diseases such as AD. Moreover, when variables which affect P3 measures such as task parameters and population differences are well controlled, the P3 ERP can differentiate between early $\mathrm{AD}$ patients and normal controls. Given these effects, it is reasonable to suppose that further refinement of the test procedures would facilitate the delineation of differences in the P3 response for the early diagnosis of $\mathrm{AD}$.

\section{References}

[1] K. C. Squires, N. K. Squires, and S. A. Hillyard, "Decisionrelated cortical potentials during an auditory signal detection task with cued observation intervals," Journal of Experimental Psychology, vol. 1, no. 3, pp. 268-279, 1975.

[2] R. Näätänen, Attention and Brain Function, Lawrence Erlbaum Associates, Hillsdale, NJ, USA, 1992.

[3] J. Polich and K. L. Herbst, "P300 as a clinical assay: rationale, evaluation, and findings," International Journal of Psychophysiology, vol. 38, no. 1, pp. 3-19, 2000.

[4] N. K. Squires, K. C. Squires, and S. A. Hillyard, "Two varieties of long latency positive waves evoked by unpredictable auditory stimuli in man," Electroencephalography and Clinical Neurophysiology, vol. 38, no. 4, pp. 387-401, 1975.

[5] J. E. Desmedt, J. Debecker, and J. Manil, "Demonstration of a cerebral electric sign associated with the detection by the subject of a tactile sensorial stimulus. The analysis of cerebral evoked potentials derived from the scalp with the aid of numerical ordinates," Bulletin de l'Academie Royale de Medecine de Belgique, vol. 5, no. 11, pp. 887-936, 1965.

[6] S. Sutton, M. Braren, J. Zubin, and E. R. John, "Evokedpotential correlates of stimulus uncertainty," Science, vol. 150, no. 3700, pp. 1187-1188, 1965.

[7] E. Halgren, P. Baudena, J. M. Clarke et al., "Intracerebral potentials to rare target and distracter auditory and visual stimuli. I. Superior temporal plane and parietal lobe," Electroencephalography and Clinical Neurophysiology, vol. 94, no. 3, pp. 191-220, 1995. 
[8] E. Halgren, P. Baudena, J. M. Clarke et al., "Intracerebral potentials to rare target and distracter auditory and visual stimuli. II. Medial, lateral and posterior temporal lobe," Electroencephalography and Clinical Neurophysiology, vol. 94, no. 4, pp. 229-250, 1995.

[9] E. Halgren, N. K. Squires, and C. L. Wilson, "Endogenous potentials generated in the human hippocampal formation and amygdala by infrequent events," Science, vol. 210, no. 4471, pp. 803-805, 1980.

[10] R. Johnson Jr., "Auditory and visual P300s in temporal lobectomy patients: evidence for modality-dependent generators," Psychophysiology, vol. 26, no. 6, pp. 633-650, 1989.

[11] R. Verleger, W. Heide, C. Butt, and D. Kompf, "Reduction of $\mathrm{P} 3 \mathrm{~b}$ in patients with temporo-parietal lesions," Cognitive Brain Research, vol. 2, no. 2, pp. 103-116, 1994.

[12] H. Horn, N. Syed, H. Lanfermann, K. Maurer, and T. Dierks, "Cerebral networks linked to the event-related potential P300," European Archives of Psychiatry and Clinical Neuroscience, vol. 253, no. 3, pp. 154-159, 2003.

[13] G. Mccarthy, M. Luby, J. Gore, and P. Goldman-Rakic, "Infrequent events transiently activate human prefrontal and parietal cortex as measured by functional MRI," Journal of Neurophysiology, vol. 77, no. 3, pp. 1630-1634, 1997.

[14] V. Menon, J. M. Ford, K. O. Lim, G. H. Glover, and A. Pfefferbaum, "Combined event-related fMRI and EEG evidence for temporal-parietal cortex activation during target detection," NeuroReport, vol. 8, no. 14, pp. 3029-3037, 1997.

[15] B. Opitz, A. Mecklinger, D. Y. Von Cramon, and F. Kruggel, "Combining electrophysiological and hemodynamic measures of the auditory oddball," Psychophysiology, vol. 36, no. 1, pp. 142-147, 1999.

[16] A. A. Stevens, P. Skudlarski, J. C. Gatenby, and J. C. Gore, "Event-related fMRI of auditory and visual oddball tasks," Magnetic Resonance Imaging, vol. 18, no. 5, pp. 495-502, 2000.

[17] E. Donchin, "Presidential Address, 1980: surprise!...surprise?" Psychophysiology, vol. 18, no. 5, pp. 493-513, 1981.

[18] M. C. E. Donchin, "Is the P300 component a manifestation of context updating?" Behavioral and Brain Sciences, pp. 357$374,1988$.

[19] J. Polich, "Habituation of P300 from auditory stimuli," Psychophysiology, vol. 17, pp. 19-28, 1989.

[20] C. Wickens, A. Kramer, L. Vanasse, and E. Donchin, "Performance of concurrent tasks: a psychophysiological analysis of the reciprocity of information-processing resources," Science, vol. 221, no. 4615, pp. 1080-1082, 1983.

[21] A. F. Kramer and D. L. Strayer, "Assessing the development of automatic processing: an application of dual-task and eventrelated brain potential methodologies," Biological Psychology, vol. 26, no. 1-3, pp. 231-267, 1988.

[22] C. J. Gonsalvez and J. Polich, "P300 amplitude is determined by target-to-target interval," Psychophysiology, vol. 39, no. 3, pp. 388-396, 2002.

[23] R. Johnson, "Event-related potential insights into the neurobiology of memory systems," in Handbook of Neuropsychology, F. Boller and J. Grafman, Eds., vol. 10, pp. 135-163, Elsevier, Amsterdam, The Netherlands, 1995.

[24] M. Fabiani, D. Karis, and E. Donchin, "Effects of mnemonic strategy manipulation in a Von Restorff paradigm," Electroencephalography and Clinical Neurophysiology, vol. 75, no. 2, pp. 22-35, 1990.

[25] A. Kok, "On the utility of P3 amplitude as a measure of processing capacity," Psychophysiology, vol. 38, no. 3, pp. 557$577,2001$.
[26] M. Kutas, G. McCarthy, and E. Donchin, "Augmenting mental chronometry: the P300 as a measure of stimulus evaluation time," Science, vol. 197, no. 4305, pp. 792-795, 1977.

[27] J. Polich, "Attention, probability, and task demands as determinants of P300 latency from auditory stimuli," Electroencephalography and Clinical Neurophysiology, vol. 63, no. 3, pp. 251-259, 1986.

[28] G. McCarthy and E. Donchin, "A metric for thought: a comparison of P300 latency and reaction time," Science, vol. 211, no. 4477, pp. 77-80, 1981.

[29] A. Pfefferbaum, C. Christensen, J. M. Ford, and B. S. Kopell, "Apparent response incompatibility effects on P3 latency depend on the task," Electroencephalography and Clinical Neurophysiology, vol. 64, no. 5, pp. 424-437, 1986.

[30] C. C. Duncan-Johnson, "P300 latency: a new metric of information processing," Psychophysiology, vol. 18, no. 3, pp. 207-215, 1981.

[31] R. Verleger, "On the utility of P3 latency as an index of mental chronometry," Psychophysiology, vol. 34, no. 2, pp. 131-156, 1997.

[32] J. Polich, L. Howard, and A. Starr, "P300 latency correlates with digit span," Psychophysiology, vol. 20, no. 6, pp. 665-669, 1983.

[33] R. Y. Emmerson, R. E. Dustman, D. E. Shearer, and C. W. Turner, "P3 latency and symbol digit performance correlations in aging," Experimental Aging Research, vol. 15, no. 3-4, pp. 151-159, 1989.

[34] J. Polich and S. Martin, "P300, cognitive capability, and personality: a correlational study of university undergraduates," Personality and Individual Differences, vol. 13, no. 5, pp. 533543, 1992.

[35] J. Polich, C. Ladish, and T. Burns, "Normal variation of P300 in children: age, memory span, and head size," International Journal of Psychophysiology, vol. 9, no. 3, pp. 237-248, 1990.

[36] N. K. Squires, G. Galbraith, and C. Aine, "Event-related potential assessment of sensory and cognitive deficits in the mentally retarded," in Human Evoked Potentials: Applications and Problems, D. Lehmann and E. Callaway, Eds., pp. 397-413, Plenum Press, New York, NY, USA, 1979.

[37] W. S. Brown, J. T. Marsh, and A. LaRue, "Event-related potentials in psychiatry: differentiating depression and dementia in the elderly," Bulletin of the Los Angeles neurological societies, vol. 47, pp. 91-107, 1982.

[38] V. Homberg, H. Hefter, and G. Granseyer, "Event-related potentials in patients with Huntington's disease and relatives at risk in relation to detailed psychometry," Electroencephalography and Clinical Neurophysiology, vol. 63, no. 6, pp. 552-569, 1986.

[39] B. F. O’Donnell, S. Friedman, J. M. Swearer, and D. A. Drachman, "Active and passive P3 latency and psychometric performance: influence of age and individual differences," International Journal of Psychophysiology, vol. 12, no. 2, pp. 187-195, 1992.

[40] J. Polich, "Normal variation of P300 from auditory stimuli," Electroencephalography and Clinical Neurophysiology, vol. 65, no. 3, pp. 236-240, 1986.

[41] D. S. Goodin, K. C. Squires, and A. Starr, "Long latency event-related components of the auditory evoked potential in dementia," Brain, vol. 101, no. 4, pp. 635-648, 1978.

[42] D. S. Goodin, K. C. Squires, B. H. Henderson, and A. Starr, "Age-related variations in evoked potentials to auditory stimuli in normal human subjects," Electroencephalography and Clinical Neurophysiology, vol. 44, no. 4, pp. 447-458, 1978. 
[43] D. S. Goodin, A. Starr, T. Chippendale, and K. C. Squires, "Sequential changes in the P3 component of the auditory evoked potential in confusional states and dementing illnesses," Neurology, vol. 33, no. 9, pp. 1215-1218, 1983.

[44] D. S. Goodin, K. C. Squires, and A. Starr, "Variations in early and late event-related components of the auditory evoked potential with task difficulty," Electroencephalography and Clinical Neurophysiology, vol. 55, no. 6, pp. 680-686, 1983.

[45] L. E. Holt, A. Raine, G. Pa, L. S. Schneider, V. W. Henderson, and V. E. Pollock, "P300 topography in Alzheimer's disease," Psychophysiology, vol. 32, no. 3, pp. 257-265, 1995.

[46] J. Polich and A. Pitzer, "P300 in early Alzheimer's disease: oddball task difficulty and modality effects," in Clinical Neurophysiology: From Receptors to Perception, EEG Supplement, G. Comi, C. H. Lucking, J. Kimura, and R. M. Rossini, Eds., pp. 281-287, Elsevier, Amsterdam, The Netherlands, 1999.

[47] J. Polich and J. Corey-Bloom, "Alzheimer's disease and P300: review and evaluation of task and modality," Current Alzheimer Research, vol. 2, no. 5, pp. 515-525, 2005.

[48] E. J. Golob, R. Irimajiri, and A. Starr, "Auditory cortical activity in amnestic mild cognitive impairment: relationship to subtype and conversion to dementia," Brain, vol. 130, no. 3, pp. 740-752, 2007.

[49] T. Frodl, H. Hampel, G. Juckel et al., "Value of event-related P300 subcomponents in the clinical diagnosis of mild cognitive impairment and Alzheimer's disease," Psychophysiology, vol. 39, no. 2, pp. 175-181, 2002.

[50] E. J. Golob, J. K. Johnson, and A. Starr, "Auditory eventrelated potentials during target detection are abnormal in mild cognitive impairment," Clinical Neurophysiology, vol. 113, no. 1, pp. 151-161, 2002.

[51] B. A. Ally, G. E. Jones, J. A. Cole, and A. E. Budson, "The P300 component in patients with Alzheimer's disease and their biological children," Biological Psychology, vol. 72, no. 2, pp. 180-187, 2006.

[52] S. S. Ball, J. T. Marsh, G. Schubarth, W. S. Brown, and R. Strandburg, "Longitudinal P300 latency changes in Alzheimer's disease," Journals of Gerontology, vol. 44, no. 6, pp. M195-M200, 1989.

[53] C. L. Lai, R. T. Lin, L. M. Liou, and C. K. Liu, "The role of event-related potentials in cognitive decline in Alzheimer's disease," Clinical Neurophysiology, vol. 121, no. 2, pp. 194-199, 2010.

[54] E. A. Werber, R. Gandelman-Marton, C. Klein, and J. M. Rabey, "The clinical use of P300 event related potentials for the evaluation of cholinesterase inhibitors treatment in demented patients," Journal of Neural Transmission, vol. 110, no. 6, pp. 659-669, 2003.

[55] C. Rosenberg, K. Nudleman, and A. Starr, "Cognitive evoked patentials (P300) in early Huntington's disease," Archives of Neurology, vol. 42, no. 10, pp. 984-987, 1985.

[56] D. S. Goodin and M. J. Aminoff, "Electrophysiological differences between subtypes of dementia," Brain, vol. 109, no. 6, pp. 1103-1113, 1986.

[57] J. V. Patterson, H. J. Michalewski, and A. Starr, "Latency variability of the components of auditory event-related potentials to infrequent stimuli in aging, Alzheimer-type dementia, and depression," Electroencephalography and Clinical Neurophysiology, vol. 71, no. 6, pp. 450-460, 1988.

[58] B. F. O'Donnell and N. K. Squires, "Evoked potential changes and neuropsychological performance in Parkinson's disease," Biological Psychology, vol. 24, no. 1, pp. 23-37, 1987.
[59] E. C. Hansch, K. Syndulko, and S. N. Cohen, "Cognition in Parkinson disease: an event-related potential perspective," Annals of Neurology, vol. 11, no. 6, pp. 599-607, 1982.

[60] B. F. O’Donnell, S. Friedman, N. K. Squires, A. Maloon, D. A. Drachman, and J. M. Swearer, "Active and passive P3 latency in dementia. Relationship to psychometric, electroencephalographic, and computed tomographic measures," Neuropsychiatry, Neuropsychology and Behavioral Neurology, vol. 3, no. 3, pp. 164-179, 1990.

[61] M. R. Newton, G. Barrett, M. M. Callanan, and A. D. Towell, "Cognitive event-related potentials in multiple sclerosis," Brain, vol. 112, no. 6, pp. 1637-1660, 1989.

[62] W. S. Pritchard, "Cognitive event-related potential correlates of schizophrenia," Psychological Bulletin, vol. 100, no. 1, pp. 43-66, 1986.

[63] E. Courchesne, "Chronology of postnatal human brain development: event-related potential, positron tomography, myelinogenesis, and synaptogenesis," in Event-Related Brain Potentials: Basic Issues and Applications, J. Rohrbaugh, R. Parasuraman, and R. Johnson, Eds., pp. 210-241, Oxford University Press, New York, NY, USA, 1990.

[64] R. W. McCarley, M. E. Shenton, B. F. O'Donnell et al., "Auditory P300 abnormalities and left posterior superior temporal gyrus volume reduction in schizophrenia," Archives of General Psychiatry, vol. 50, no. 3, pp. 190-197, 1993.

[65] H. Begleiter and B. Porjesz, "Neurophysiological phenotypic factors in the development of alcoholism," in The Genetics of Alcoholism, H. Begleiter and B. Kissin, Eds., pp. 269-293, Oxford University Press, New York, NY, USA, 1995.

[66] G. E. Bruder, C. E. Tenke, J. W. Stewart et al., "Brain eventrelated potentials to complex tones in depressed patients: relations to perceptual asymmetry and clinical features," Psychophysiology, vol. 32, no. 4, pp. 373-381, 1995.

[67] N. Boutros, H. Nasrallah, R. Leighty, M. Torello, P. Tueting, and S. Olson, "Auditory evoked potentials, clinical vs. research applications," Psychiatry Research, vol. 69, no. 2-3, pp. 183195, 1997.

[68] A. Pfefferbaum, B. G. Wenegrat, and J. M. Ford, "Clinical application of the P3 component of event-related potentials. II. Dementia, depression and schizophrenia," Electroencephalography and Clinical Neurophysiology, vol. 59, no. 2, pp. 104-124, 1984.

[69] D. E. J. Linden, "The P300: where in the brain is it produced and what does it tell us?" Neuroscientist, vol. 11, no. 6, pp. 563576, 2005.

[70] E. Courchesne, S. A. Hillyard, and R. Galambos, "Stimulus novelty, task relevance and the visual evoked potential in man," Electroencephalography and Clinical Neurophysiology, vol. 39, no. 2, pp. 131-143, 1975.

[71] K. Alho, I. Winkler, C. Escera et al., "Processing of novel sounds and frequency changes in the human auditory cortex: magnetoencephalographic recordings," Psychophysiology, vol. 35, no. 2, pp. 211-224, 1998.

[72] P. Baudena, E. Halgren, G. Heit, and J. M. Clarke, "Intracerebral potentials to rare target and distracter auditory and visual stimuli. III. Frontal cortex," Electroencephalography and Clinical Neurophysiology, vol. 94, no. 4, pp. 251-264, 1995.

[73] R. T. Knight, D. Scabini, D. L. Woods, and C. C. Clayworth, "Contributions of temporal-parietal junction to the human auditory P3," Brain Research, vol. 502, no. 1, pp. 109-116, 1989.

[74] A. Mecklinger and P. Ullsperger, "The P300 to novel and target events: a spatio-temporal dipole model analysis," NeuroReport, vol. 7, no. 1, pp. 241-245, 1995. 
[75] M. D. Polo, C. Escera, E. Yago, K. Alho, A. Gual, and C. Grau, "Electrophysiological evidence of abnormal activation of the cerebral network of involuntary attention in alcoholism," Clinical Neurophysiology, vol. 114, no. 1, pp. 134-146, 2003.

[76] T. Lepistö, M. Soininen, R. Čeponiene, F. Almqvist, R. Näätänen, and E. T. Aronen, "Auditory event-related potential indices of increased distractibility in children with major depression," Clinical Neurophysiology, vol. 115, no. 3, pp. 620 $627,2004$.

[77] V. Gumenyuk, Electrophysiological and behavioral indices of distractibility in school-age children, Ph.D. thesis, Department of Psychology, University of Helsinki, Helsinki, Finland, 2005.

[78] M. L. Kaipio, K. Alho, I. Winkler, C. Escera, O. Surma-Aho, and R. Näätänen, "Event-related brain potentials reveal covert distractibility in closed head injuries," NeuroReport, vol. 10, no. 10, pp. 2125-2129, 1999.

[79] M. L. Kaipio, M. Cheour, R. Čeponiené, J. Öhman, P. Alku, and R. Näätänen, "Increased distractibility in closed head injury as revealed by event- related potentials," NeuroReport, vol. 11, no. 7, pp. 1463-1468, 2000.

[80] G. Juckel, F. Clotz, T. Frodl et al., "Diagnostic usefulness of cognitive auditory event-related P300 subcomponents in patients with Alzheimers disease?" Journal of Clinical Neurophysiology, vol. 25, no. 3, pp. 147-152, 2008.

[81] S. Yamaguchi, H. Tsuchiya, S. Yamagata, G. Toyoda, and S. Kobayashi, "Event-related brain potentials in response to novel sounds in dementia," Clinical Neurophysiology, vol. 111, no. 2, pp. 195-203, 2000.

[82] R. Näätänen, A. W. K. Gaillard, and S. Mäntysalo, "Early selective-attention effect on evoked potential reinterpreted," Acta Psychologica, vol. 42, no. 4, pp. 313-329, 1978.

[83] R. Näätänen and P. T. Michie, "Early selective-attention effects on the evoked potential: a critical review and reinterpretation," Biological Psychology, vol. 8, no. 2, pp. 81-136, 1979.

[84] R. Hari, M. Hamalainen, and R. Ilmoniemi, "Responses of the primary auditory cortex to pitch changes in a sequence of tone pips: neuromagnetic recordings in man," Neuroscience Letters, vol. 50, no. 1-3, pp. 127-132, 1984.

[85] M. Scherg, J. Vajsar, and T. W. Picton, "A source analysis of the late human auditory evoked potentials," Journal of Cognitive Neuroscience, vol. 1, no. 4, pp. 336-355, 1989.

[86] C. Alain, D. L. Woods, and R. T. Knight, "A distributed cortical network for auditory sensory memory in humans," Brain Research, vol. 812, no. 1-2, pp. 23-37, 1998.

[87] R. Näätänen, "Mismatch negativity: clinical research and possible applications," International Journal of Psychophysiology, vol. 48, no. 2, pp. 179-188, 2003.

[88] R. Näätänen, P. Paavilainen, T. Rinne, and K. Alho, “The mismatch negativity (MMN) in basic research of central auditory processing: a review," Clinical Neurophysiology, vol. 118, no. 12, pp. 2544-2590, 2007.

[89] R. Näätänen and C. Escera, "Mismatch negativity: clinical and other applications," Audiology and Neuro-Otology, vol. 5, no. 3-4, pp. 105-110, 2000.

[90] I. Czigler, G. Csibra, and A. Csontos, "Age and inter-stimulus interval effects on event-related potentials to frequent and infrequent auditory stimuli," Biological Psychology, vol. 33, no. 2-3, pp. 195-206, 1992.

[91] D. L. Woods, "Auditory selective attention in middle-aged elderly subjects: an event-related brain potential study," Electroencephalography and Clinical Neurophysiology, vol. 84, no. 5, pp. 456-468, 1992.
[92] E. Pekkonen, T. Rinne, K. Reinikainen, T. Kujala, K. Alho, and R. Näätänen, "Aging effects on auditory processing: an eventrelated potential study," Experimental Aging Research, vol. 22, no. 2, pp. 171-184, 1996.

[93] E. Pekkonen, V. Jousmaki, J. Partanen, and J. Karhu, "Mismatch negativity area and age-related auditory memory," Electroencephalography and Clinical Neurophysiology, vol. 87, no. 5, pp. 321-325, 1993.

[94] V. A. Kazmerski, D. Friedman, and W. Ritter, "Mismatch negativity during attend and ignore conditions in Alzheimer's disease," Biological Psychiatry, vol. 42, no. 5, pp. 382-402, 1997.

[95] E. Pekkonen, "Mismatch negativity in aging and in Alzheimer's and Parkinson's disease," Audiology and NeuroOtology, vol. 5, no. 3-4, pp. 216-224, 2000.

[96] E. Pekkonen, V. Jousmaki, M. Kononen, K. Reinikainen, and J. Partanen, "Auditory sensory memory impairment in Alzheimer's disease: an event-related potential study," NeuroReport, vol. 5, no. 18, pp. 2537-2540, 1994.

[97] E. Pekkonen, I. P. Jääskeläinen, T. Erkinjuntti et al., "Preserved stimulus deviance detection in Alzheimer's disease," NeuroReport, vol. 12, no. 8, pp. 1649-1652, 2001.

[98] K. S. Brønnick, H. Nordby, J. P. Larsen, and D. Aarsland, "Disturbance of automatic auditory change detection in dementia associated with Parkinson's disease: a mismatch negativity study," Neurobiology of Aging, vol. 31, no. 1, pp. 104 $113,2010$.

[99] S. Savolainen, J. Karhu, A. Pääkkönen et al., "Auditory eventrelated potentials differentiate patients with normal pressure hydrocephalus and patients with concomitant Alzheimer's disease verified by brain biopsy," NeuroReport, vol. 12, no. 1, pp. 33-37, 2001. 


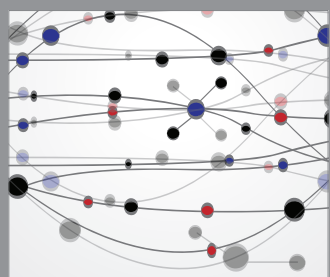

The Scientific World Journal
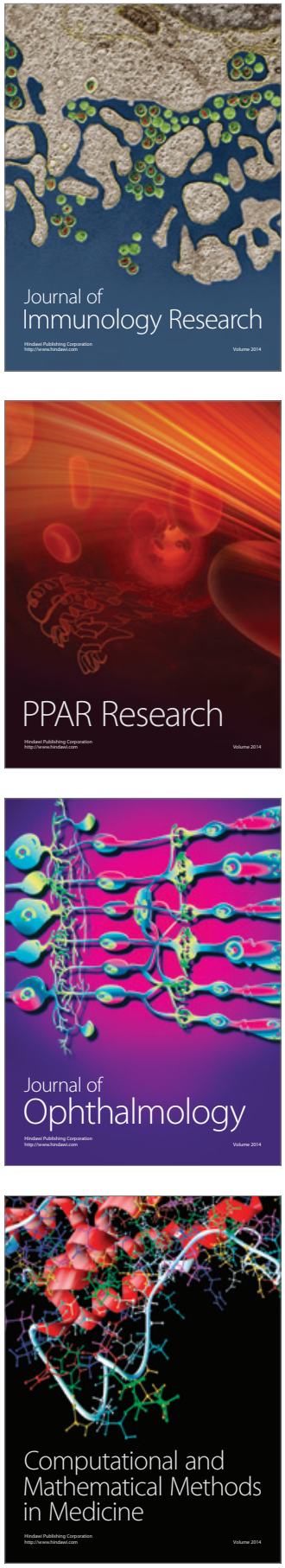

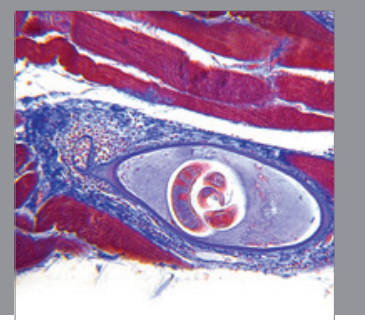

Gastroenterology

Research and Practice
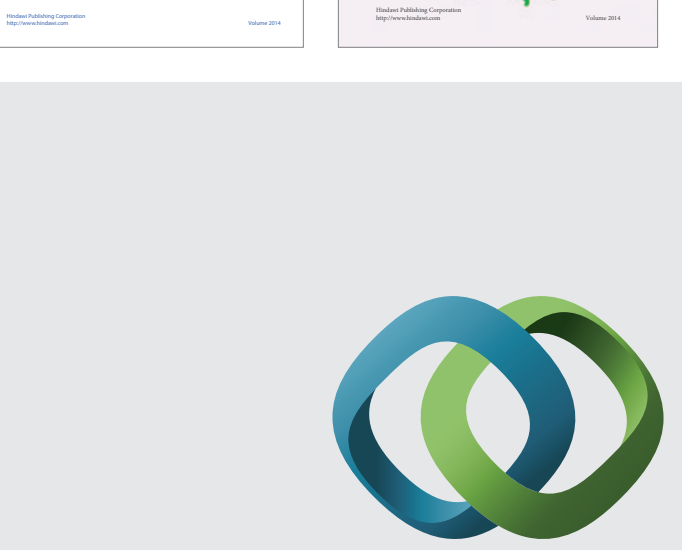

\section{Hindawi}

Submit your manuscripts at

http://www.hindawi.com
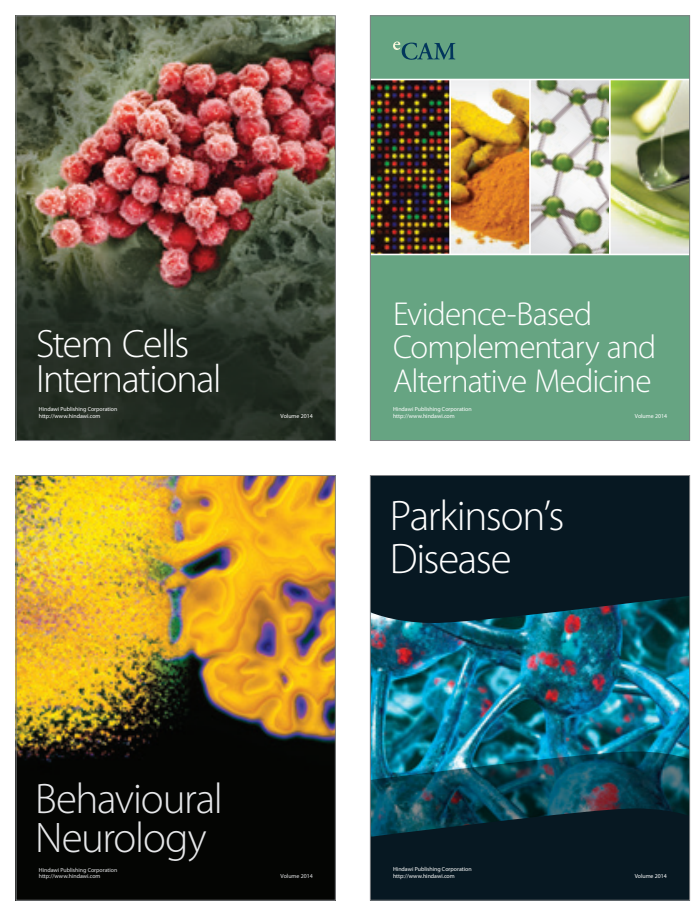

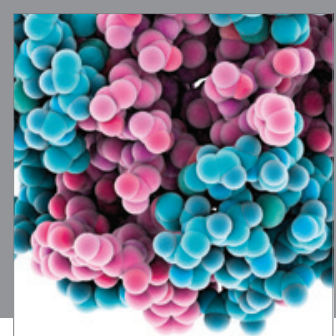

Journal of
Diabetes Research

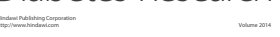

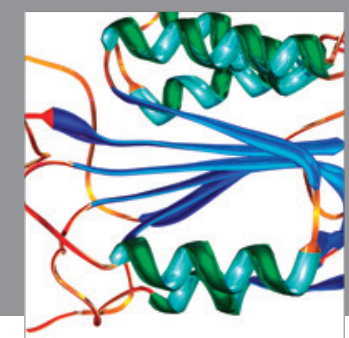

Disease Markers
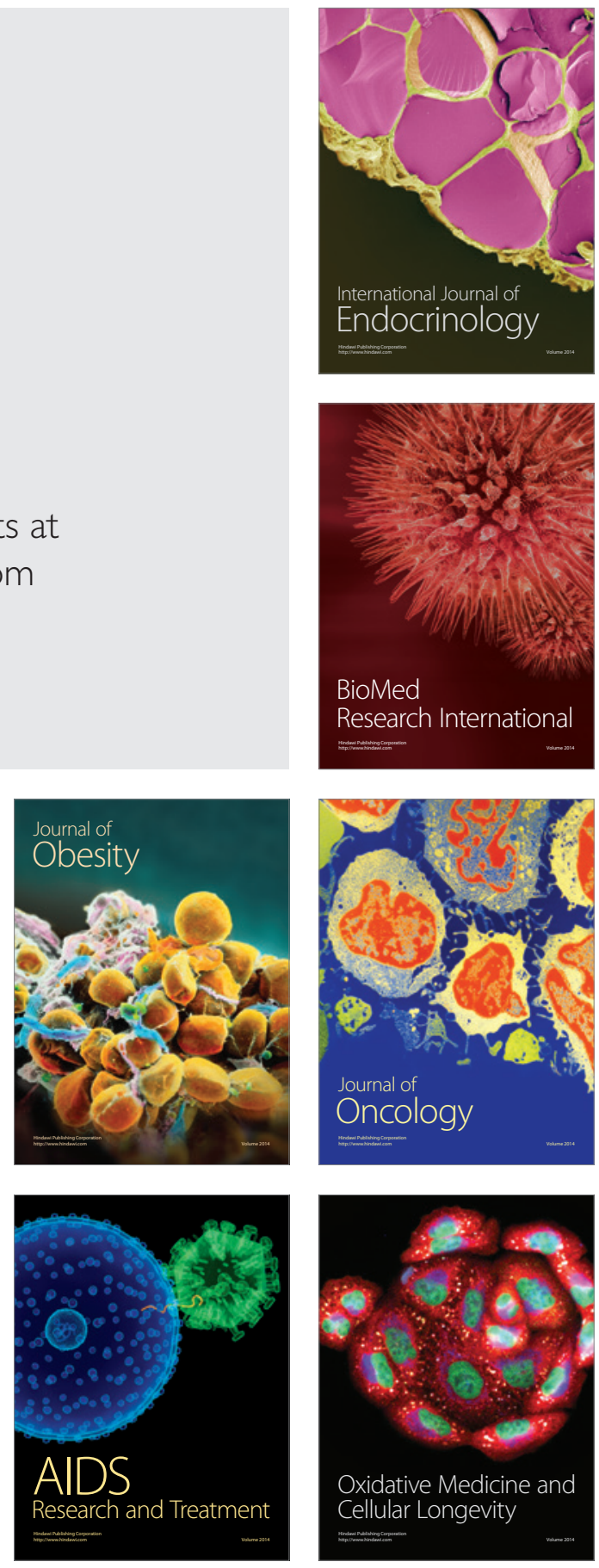